\title{
A PROSPECTIVE STUDY OF SURGICAL MANAGEMENT OF DIAPHYSEAL FRACTURES OF FEMUR IN CHILDREN AGED BETWEEN 5 TO 16 YEARS USING ELASTIC STABLE INTRA MEDULLARY NAILING
}

Prabhakar Venkataramana ${ }^{1}$, Siddarth Mahesh $^{2}$, Srinivas Nagendra $\mathrm{G}^{3}$

\section{HOW TO CITE THIS ARTICLE:}

Prabhakar Venkataramana, Siddarth Mahesh, Srinivas Nagendra G. "A Prospective Study of Surgical Management of Diaphyseal Fractures of Femur in Children aged between 5 to 16 years using Elastic Stable Intra Medullary Nailing". Journal of Evolution of Medical and Dental Sciences 2014; Vol. 3, Issue 09, March 3;

Page: 2268-2286, DOI: 10.14260/jemds/2014/2137

ABSTRACT: BACKGROUND: Elastic stable intramedullary nailing for the treatment of Pediatric Femur diaphyseal fractures was introduced by Pr'evot and colleagues in 1979. The technique offers several advantages, including better reduction, dynamic axial stabilization, shorter hospitalization with early rehabilitation and low rate of complications. OBJECTIVES: To study the union rates and functional outcome of closed reduction and internal fixation of pediatric diaphyseal fractures of femur with TENS. DESIGN: PROSPECTIVE STUDY. SETTING: AT VIMS GOVERNMENT HOSPITAL BELLARY. METHODS: 30 children between ages 5 to 16 years admitted to the Department of Orthopedics at Vijayanagar Institute of Medical Sciences, Bellary with diaphyseal fractures of femur during the period from NOVEMBER 2010 to SEPTEMBER 2012 are selected. All patients were followed up for an average of 6 months. Outcome was assessed using TENS SCORING SYSTEM USED BY FLYNN et al. RESULTS: The selected patients evaluated thoroughly clinically and radiologically. The fractures were treated BY CLOSED REDUCTION AND INTERNAL FIXATION WITH ELASTIC STABLE INTRAMEDULLARY NAILING. Results of the entire patients were followed up for an average of 6 months. Our series consisted of 30 patients, 24 male and only 6 female. Most common fracture pattern of femur was spiral. 23 fractures healed within an average duration of 10 to 12 weeks following surgery. There was superficial infection in 1 case, 2 cases had LLD $<2 \mathrm{~cm} \& 1$ femur case had nail backing out distally which was treated with second surgery for implant removal after complete union of fracture. 2 cases had varus angulation \& 1 case had valgus angulation. All patients had full range of hip and ankle motion in the present study and $4(13.33 \%)$ patients had mild restriction in knee flexion at 12 weeks. CONCLUSION: Based on our experience and results, we conclude that ELASTIC STABLE INTRAMEDULLARY NAILING technique is an ideal method for treatment of pediatric femoral diaphyseal fractures. It gives elastic mobility promoting rapid union at fractures site and stability which is ideal for early mobilization. It gives lower complication rate, good outcome when compared with other methods of treatment.

KEYWORDS: Diaphyseal femur, Titanium Elastic Nailing System, Elastic Stable Intramedullary Nailing.

INTRODUCTION: Treatment of pediatric fractures dramatically changed in 1982, when Métaizeau and the team from Nancy, France, developed the technique of flexible stable intramedullary pinning (FSIMP) using titanium pins ${ }^{1,2}$. In the last two decades there was an increased interest in the operative treatment of pediatric fractures, although debate persisted over its indications ${ }^{3}$.

Femoral shaft fractures account for $1.6 \%$ of all pediatric injuries. In children 5 years or younger, early closed reduction and application of spica cast is an ideal treatment for most diaphyseal 
fracture. In skeletally mature adolescents, use of antegrade solid intramedullary rod has become standard treatment. But, the best treatment for children between five to sixteen years of age is still debated. Compared with younger children, patients in this intermediate age group have high risk of shortening and malunion when conservative measures used 4 .

Children managed with traction and spica cast as a treatment modality has to undergo various adverse physical, social, psychological and financial consequences, of prolonged immobilization. Various other modalities include external fixation, plates and screws, use of solid antegrade intramedullary nail are available. However, the risk of certain complications, particularly pintract infection and refractures after external fixation or osteonecrosis with solid nails 5,6 .

In the past seven years fixation with flexible intramedullary nails have become popular technique, for stabilizing femoral fracture in school aged children ${ }^{6,7}$. ESIN fixation system is a simple, effective and minimally invasive technique. It gives stable fixation with rapid healing and prompt return of child to normal activity. This study was intended to assess the results following treatment of fracture shaft of femur by flexible intra medullary nail or elastic stable intramedullary technique ${ }^{8}$.

Elastic stable intramedullary nailing of long bone fractures in the skeletally immature has gained widespread popularity because of its clinical effectiveness and low risk of complications. Many studies have supported the use of this technique in the femur, citing advantages that include closed insertion, preservation of the fracture hematoma, and a physeal-sparing entry point.7, 9 The purpose of this study was to present our results following fixation of unstable femur shaft fractures with ESIN.

MATERIALS AND METHODS: All children and adolescent patients between 5-16 years of age with diaphyseal fractures of femur admitted at VIMS hospital, Bellary - meeting the inclusion and the exclusion criteria (as given below) during the study period were the subjects for the study.

\section{Inclusion criteria:}

- Children and adolescent patients from 5 to 16 year with diaphyseal femur fracture.

- children of both the sexes are included in the study

- children with closed diaphyseal fractures of femur

- Patient fit for surgery

\section{Exclusion criteria:}

- Patients less than 5 years of age and more than 16 years of age.

- Patients unfit for surgery

- segmental fractures

- Patients not willing for surgery

- Patients medically unfit for surgery

As soon as the patient was brought to casualty, patient's airway, breathing and circulation were assessed. Then a complete survey was carried out to rule out other significant injuries. Plain radiographs of AP and lateral views of - the thigh including hip and knee joints to assess the extent of fracture comminution, the geometry and the dimensions of the fracture.

On admission to ward, a detailed history was taken, relating to the age, sex, and occupation, mode of injury, past and associated medical illness. Routine investigations were done for all patients. Patients were operated as early as possible once the general condition of the patient was stable and patient was fit for surgery. 


\section{ORIGINAL ARTICLE}

After prior informed consent, a pre-operative anesthetic evaluation is done. Pre-op planning of fixation is made.

\section{PREOPERATIVE PLANNING:}

\section{Nail Size}

Nail width: The diameter of the individual nail is selected as per

\section{1) Flynn et al's formula.}

Diameter of nail= width of the narrowest point of the medullary canal on AP and LATERAL view X $0.4 \mathrm{~mm}$

\section{2) Intra operative assessment}

Nail length: Lay one of the selected nails over the thigh/leg, and determine that it is of the appropriate length by fluoroscopy. The nail for femur should extend from the level of the distal femoral physis to a point approximately $2 \mathrm{~cm}$ distal to the capital femoral physis and $1 \mathrm{~cm}$ distal to the greater trochanteric physis.

\section{Preoperative preparation of patients:}

- Patients were kept fasting over night before surgery.

- Adequate amount of compatible blood was kept ready for any eventuality.

- The whole of the extremity below the umbilicus, including the genitalia was prepared when required

- A systemic antibiotic, usually a $3^{\text {rd }}$ generation cephalosporin was administered 1 hour before surgery.

Under anesthesia, closed reduction and internal fixation with TENS nails done under c-arm guidance.

\section{PROCEDURE FOR TENS NAILING OF DIAPHYSEAL FRACTURE OF FEMUR RETROGRADE FIXATION}

General/Spinal anesthesia is administered, and patient is placed in supine on a radiolucent table. The operative extremity is then prepped and draped free. Identify the physis by fluoroscopy, and mark its location on the skin. A 2 to $2.5 \mathrm{~cm}$ longitudinal skin incision was made over the medial and lateral surface of the distal femur, starting $2 \mathrm{~cm}$ proximal to the distal femoral epiphyseal plate; a hemostat was used to split the soft tissue down to the bone, following which a $3.2 \mathrm{~mm}$ drill bit was used at a point $2.5 \mathrm{~cm}$ proximal to the distal femoral growth plate to open the cortex at a right angle; the drill was then inclined $10^{\circ}$ to the distal femoral cortex. A nail was introduced with a T-handle by rotation movements of the wrist.

Under image intensifier control, the nail was driven with rotatory movement or with a hammer to the fracture site which was aligned to anatomical or near anatomical position with proper attention to limb rotation and length. By rotation movements of the T-handle with or without limb manipulation, the nail was directed to the proximal fragment which was pushed into better alignment by the nail. At the same time the second nail was advanced to enter the proximal fragment and in the meantime any traction was released to avoid any distraction, and both nails were pushed further till their tips became fixed into the cancellous bone of the proximal femoral metaphysis without reaching 
the epiphyseal plate. The tips of the nail that entered the lateral femoral cortex should come to rest just distal to the trochanteric epiphysis. The opposite nail should be at the same level towards the calcar region; too short nails should be avoided.

The two-nail construct should be in a symmetrical alignment face to face with the maximum curvature of the nails at the level of the fracture

Distally the nails were cut leaving only $0.5-1 \mathrm{~cm}$ outside the cortex. The extra osseous portion of the nails was kept as it was or slightly bent away from the bone to facilitate removal later on. In all cases care was taken to use nails with similar diameters, to use the largest possible diameter, and to use the double $\mathrm{C}$ construct to ensure 3-point fixation.

\section{Postoperative Care:}

- Patients were kept nil orally 4 to 6 hours post operatively

- IV fluids/blood transfusions were given as needed

- Analgesics were given according to the needs of the patient

- The limb was kept elevated over a pillow.

- IV antibiotics were continued for 5 days and switched over to oral antibiotics on the 5th day and continued till the 12th day.

- Sutures were removed on the $12^{\text {th }}$ postoperative day and patients were discharged.

Post-operatively, patients are immobilized with long leg cast with a pelvic band for femur fracture or above knee POP cast for tibia fracture for 6 weeks and such immobilization was continued for another 2-3 weeks based on radiological assessment.

The period of immobilization was followed by active hip and knee/knee and ankle mobilization with non-weight bearing crutch walking

Full weight bearing is started by 8 - 12 weeks depending on the fracture configuration and callus response.

\section{FOLLOW UP:}

Assessment done at 6,12 and 24 weeks.

At each follow up patients are assessed clinically, radiologically and the complications are noted.

\section{RESULTS:}

Age incidence: In the present study 16(53.3\%) of the patients were 5-8 years, 7 (23.3\%)were 9 to 12 years and $7(23.3 \%)$ were 13 to 16 years age group with the average age being 9.03 years.

Sex incidence: There were $6(20 \%)$ girls and $24(80 \%)$ boys in the present study. The sex incidence is comparable to other studies in the literature.

Mode of Injury: In the present study RTA was the most common mode of injury accounting for 18 $(60.0 \%)$ cases, self-fall accounted for $10(33.3 \%)$ cases and fall from height accounted for 2 (6.66\%) of the cases.

Pattern of Facture: In our study, transverse fractures accounted for 11(36.6\%) cases, oblique fractures - $9(30.0 \%)$, spiral fractures $-10(33.3 \%)$ and there were no segmental fractures 
Level of Fracture: Fractures involving the middle 1/3rd accounted for 15 (50\%) cases, proximal $1 / 3^{\text {rd }}-10(33.3 \%)$ and there are $5(16.66)$ distal $1 / 3^{\text {rd }}$ fractures in our study.

Time interval between trauma and surgery: In the present series, 16 (53.3\%) patients underwent surgery within 2 days after trauma, $8(26.6 \%)$ in $3-4$ days, $4(13.3 \%)$ in $5-7$ days and $2(6.6 \%)$ patients after 7 days.

Duration of surgery in minutes: In the present study, duration of surgery was $<30$ mins in 5(16.6\%) case, 30-60 mins in 16 (53.3\%) cases, 61-90 mins in another 7 (23.3\%) cases and 91-120 mins in $2(6.7 \%)$ of the cases.

Post-operative immobilization/mobilization: In our study, 24 (80\%) cases were immobilized (long leg slab with a pelvic band for femur fracture postoperatively for 2 weeks and such immobilization was for 4 weeks in rest of the $6(20 \%)$ of the cases with associated injuries.

The period of immobilization was followed by active hip and knee/knee and ankle mobilization with non-weight crutch walking. The advantage of the present study was early mobilization of the patients.

Duration of stay in the hospital: The duration of stay in the hospital $\leq 7$ days for $21(70 \%)$ patients, 8-10 days for 3 (10\%), 11-15 days for 4 (13.3\%) and 2 (6.6\%) patients stayed for more than 15 days with associated injuries. The average duration of hospital stay in the present study is 6.6 days.

Time for union: In our study union was achieved in $<3$ months in $23(76.6 \%)$ of the patients and $3-$ 4.5 months in $5(16.6 \%)$ and 4.5- 6 months in 2(6.6\%). Average time to union was 10.2 weeks.

Time of full weight bearing. In the present study, unsupported full weight bearing walking was started in $<12$ weeks for $23(76.6 \%)$ of the patients, between 12 and 18 weeks in $5(16.6 \%)$ and at 20 weeks in $2(6.6 \%)$ patient. The average time of full weight bearing was 12.06 weeks.

\section{COMPLICATIONS:}

Pain at the site of nail insertion: In the present study, 4(13.3\%) patients had developed pain at site of nail insertion during initial follow up evaluation which resolved completely in all of them by the end of 16 weeks.

Infection: Superficial infection was seen in $1(3.3 \%)$ case in our study which was controlled by antibiotics.

Range of motion: All patients had full range of hip and ankle motion in the present study and 4 $(13.33 \%)$ patients had mild restriction in knee flexion at 12 weeks, but normal range of knee flexion was achieved at 6 months.

Limb length discrepancy: This is the most common sequelae after femoral shaft fractures in children and adolescents. 2(6.66\%) patients had lengthening (femur $-1.2 \mathrm{~cm}$ ). No patient in our study had major limb length discrepancy (i.e. $> \pm 2 \mathrm{~cm}$ ).

MALALLIGNMENT: Some degree of angular deformity is frequent after femoral shaft fractures in children, but this usually remodels after growth.

Varus/valgus malalignment: $2(6.7 \%)$ patients presented with varus ( $8^{0}$ and $\left.6^{0}\right)$ angulation, $1(3.3 \%)$ patient presented with valgus $\left(6^{\circ}\right)$ angulation.

Other complications: Bursa over tip of the nail was noticed in 3 cases in our study; Implant removal is done in all the 3 cases. 
Assessment of Outcome: In the present study, the final outcome was excellent in 20 (66.66\%) cases, satisfactory in 10 (33.33\%) cases and there were no poor outcome cases based on FLYNN CRITERION. TENS outcome score (Flynn et al) ${ }^{9}$

\begin{tabular}{|c|c|c|c|}
\hline RESULTS & \multirow{2}{*}{ Excellent } & \multirow{2}{*}{ Satisfactory } & \multirow{2}{*}{ Poor } \\
\hline VARIABLES at 24 weeks & & & \\
\hline Limb-length inequality & $<1.0 \mathrm{~cm}$ & $<2.0 \mathrm{~cm}$ & $>2.0 \mathrm{~cm}$ \\
\hline Malallignment & 5 degrees & 10 degrees & $>10$ degrees \\
\hline Unresolved pain & absent & Absent & present \\
\hline Other complications & None & Minor and resolved & Major and lasting morbidity \\
\hline
\end{tabular}

Statistical Analysis: Descriptive statistics like numbers, percentages, average, standard deviations, were used. Data was presented in the form of tables and graphs wherever necessary.

DISCUSSION: The treatment of closed femoral shaft fractures in children has traditionally been traction and casting but children in the 5-15 year age group experienced a change in trend. Prolonged immobilization, short hospitalization of the child, concerns of the parents, risk of joint stiffness and delayed functional recovery have all prompted orthopaedicians to advocate for intramedullary nailing in form of ender's nail or titanium nails. The ideal implant should be simple, load sharing, and allow mobilization as well as maintain length until a callus forms.

Ender nails are stainless steel implants that proved to be inadequate for adult femoral and tibial fractures but may be effective for pediatric fractures although they may be not elastic enough as their modulus of elasticity is higher than titanium nails.

TENs are more elastic, thus limiting the amount of permanent deformation during nail insertion; they promote healing by limiting stress shielding in addition to their biocompatibility without metal sensitivity reactions ${ }^{7,9,10-12}$.

The principle of Ender nail fixation is canal filling with the nails, while TENs work by balancing the forces between the two opposing flexible implants. To achieve this balance, the nail diameter should be $40 \%$ of the narrowest canal diameter or more; the nails should assume a double$\mathrm{C}$ construct. They should have similar smooth curve and same level entry points 7,13 .

The development of the TENs fixation method has put an end to criticism of the surgical treatment of pediatric long bone fractures, as it avoids any growth disturbance by preserving the epiphyseal growth plate, it avoids bone damage or weakening through the elasticity of the construct, which provides a load sharing, biocompatible internal splint, and finally it entails a minimal risk of bone infection. The low incidence of complications reported in this study especially for malunion and limb-length discrepancy may be related to exclusion of extreme proximal and distal femoral fractures, meticulous adhesion to all technical requirements of the technique, and the use of postoperative immobilization in cases with concern about stability.

In our opinion, the exact value of TENs fixation of extreme proximal or distal femoral fractures should be evaluated on a large scale. The low incidence of complications reported in this study especially for malunion and limb-length discrepancy may be related to exclusion of extreme proximal and distal femoral fractures, meticulous adhesion to all technical requirements of the technique, and the use of postoperative immobilization in cases with concern about stability. 
In our study union was achieved in $<3$ months in $23(76.6 \%)$ of the patients and $3-4.5$ months in $5(16.6 \%)$ and 4.5- 6 months in 2(6.6\%). Average time to union was 10.2 weeks.

Oh C.W et al reported average time for union as 10.5 weeks. $^{14}$

Aksoy $\mathrm{C}$, et al compared the results of compression plate fixation and flexible intramedulalry nail insertion. Average time to union was 7.7 (4 to 10) months in the plating group and 4 ( 3 to 7) months for flexible intramedullary nailing. ${ }^{15}$

In our study, closed reduction of the fracture, leading to preservation of fracture hematoma, improved biomechanical stability and minimal soft tissue dissection led to rapid union of the fracture compared to compression plate fixation.

In the present study, unsupported full weight bearing walking was started in $<12$ weeks for $23(76.6 \%)$ of the patients, between 12 and 18 weeks in $5(16.6 \%)$ and at 20 weeks in $2(6.6 \%)$ patient.

The average time of full weight bearing was 12.06 weeks.

Wudbhav N. Sankar et al. in their study allowed full weight bearing between 5.7-11.6 weeks an average of 8.65 weeks. ${ }^{16}$

Limb length discrepancy: This is the most common sequelae after femoral shaft fractures in children and adolescents. 2(6.66\%) patients had lengthening (femur $-1.2 \mathrm{~cm}$ ). No patient in our study had major limb length discrepancy (i.e. $> \pm 2 \mathrm{~cm}$ ).

Beaty et al. reported, two patients had overgrowth of more than $2.5 \mathrm{~cm}$ necessitating epiphysiodhesis, after conservative treatment. ${ }^{3}$

Ozturkman Y. et al observed mean leg lengthening of $7 \mathrm{~mm}$ in 4 (5\%) patients and mean shortening of $6 \mathrm{~mm}$ in $2(2.5 \%)$ children. ${ }^{17}$

Cramer KE, et al noted average limb lengthening of $7 \mathrm{~mm}$ (range $1-19 \mathrm{~mm}$ ) in their study. Clinically significant limb discrepancy $(>2 \mathrm{~cm})$ did not occur in any patient in their study. ${ }^{18}$

Wudbhav N.Sankar in their study of 19 tibial shaft fractures reported no leg length discrepancy. ${ }^{19}$

John Ferguson et al noted more than $2 \mathrm{~cm}$ shortening in 4 children after spica treatment of pediatric femoral shaft fracture. In the present study, limb length discrepancy of more than $10 \mathrm{~mm}$ was present in $2(10 \%)$ cases. $^{20}$

Comparing to limb length discrepancy in conservative methods, limb length discrepancy in our study was within the acceptable limits

In the present study, the final outcome was excellent in $20(66.66 \%)$ cases, satisfactory in 10 $(33.33 \%)$ cases and there were no poor outcome cases.

Gamal El Adl et al. in their study of 66 children with 48 femoral and 25 tibial shaft fractures reported (75.8\%) excellent, $24.2 \%$ satisfactory and no poor results. ${ }^{19}$

J. M. Flynn et al. treated 234 femoral shaft fractures and the outcome was excellent in $150(65 \%)$ cases, satisfactory in $57(25 \%)$ cases and poor in $23(10 \%)$ of the cases. ${ }^{9}$

Wudbhav N.Sankar in their study of 19 tibial shaft fractures reported 12 (63.15\%) excellent, 6 (31.57\%) satisfactory and $1(5.26 \%)$ poor results. ${ }^{16}$

K C Saikia et al. in their study of 22 children with femoral diaphyseal fractures reported 13 (59\%) excellent, 6 (27.2\%) satisfactory and 3(13.6\%) poor results. ${ }^{21}$ 
CONCLUSION: Based on our experience and results, we conclude that ELASTIC STABLE INTRAMEDULLARY NAILING technique is an ideal method for treatment of pediatric femoral diaphyseal fractures. It gives elastic mobility promoting rapid union at fractures site and stability which is ideal for early mobilization. It gives lower complication rate, good outcome when compared with other methods of treatment.

Is a simple, easy, rapid, reliable and effective method for management of pediatric femoral and tibial fractures between the age of 5 to 16 years, with shorter operative time, lesser blood less, lesser radiation exposure, shorter hospital stay, and reasonable time to bone healing.

Because of early weight bearing, rapid healing and minimal disturbance of bone growth, ESIN may be considered to be a physiological method of treatment.

Use of ESINs for definitive stabilization of femoral and tibial shaft fractures in children is a reliable, minimally invasive, and physeal-protective treatment method. Our study results provide new evidence that expands the inclusion criteria for this treatment and shows that ESINs can be successfully used regardless of fracture location and fracture pattern.

\section{REFERENCES:}

1. Metaizeau JP. Osteosynthesis in children: techniques and indications (in French) Chir Pédiatr 1983; 69: 495-511.

2. Metaizeau JP. Osteosynthèse chez l' Enfant: Embrochage Centro Médullaire Elastique Stable. Sauramps Med Dif - fusion Vigot, Montpellier, 1988, pp 61-102.

3. Beaty JH, Austin SM, Warner WC et al. Interlocking intramedullary nailing of femoral shaft fractures in adolescents: preliminary results and complications. J Pediatr Orthop 1994; 14: 178183.

4. Scheri SA, Miller L, Lively N, Russinof S, Sullivan M Tornetta P III. Et al. Accidental and nonaccidental femur fractures in children. Clin Orthop and Rel Research 2000; 376:96-105.

5. Momberger N, Stevens P, Smith J, Santora S, Scott S and Anderson J. Intramedullary nailing of femoral fractures in adolescents. J Pediatr Orthop 2000; Vol.20:482-484.

6. Lee SS, Mahar AT and Nowton PO. Ender nail fixation of pediatric femur fractures. A biomechanical analysis. J Pediatr Orthop 2001; Vol. 21: 442-445.

7. Ligier JN, Metaizeau JP, Prevot J and Lascombes P. Elastic stable intramedullary nailing of femur fracture in children. J Bone \& Joint Surg (Br) 1988; Vol 70B: 74-7.

8. Townsend DR and Hoffinger S. Intramedullary nailing of femoral shaft fractures in children via the trichanteric tip. Clin Orthop and Rel Research 2000; 376: 113-118.

9. Flynn JM, Hresko T, Reynolds RA, Blasier RD, Davidson R, Kasser J. Titanium elastic nails for pediatric femur fractures-- a multicenter study of early results with analysis of complications. J Pediatr Orthop 2001; 21(1):4-8

10. Heinrich SD, Drvaric DM, Darr K, MacEwen GD. The operative stabilization of paediatric diaphyseal femoral fractures: a prospective analysis. J Pediatr Orthop 1994; 14: 501-507.

11. Hierholzer S, Hierholzer G (eds). Internal fixation and metal allergy in: Clinical Investigations, Immunology and Histology of the Implant-Tissue Interface. George Thieme Verlag, New York, 1992, pp 5-7.

12. Sanders JO, Browner RH, Mooney JP et al. Treatment of femoral fractures in children by pediatric orthopedists: Results of a 1998 survey. J Pediatr Orthop 2001; 21: 436-444. 
13. Ligier JN, Métaizeau JP, Prévot J, Lascombes P. Elastic stable intramedullary pinning of long bone shaft fractures in children. Z Kinderchir 1985; 40: 209-212.

14. Oh CW, Park BC, Kim PT, Kyung HS, Kim SJ and Inn JC. Retrograde flexible intramedullary nailing in children's femoral fractures. Int Orthop 2002; 26 (1): 52-5.

15. Aksoy C, Caolar O, Yazyoy M and Surat A. 'pediatric femoral fractures A comparison of compression plate fixation and flexible intramedullary nail fixation'. J Bone \& Joint Surg (Br) 2003; 85-B: Supp III: 263 pp.

16. Wudbhav N Sankar, Kristofer J Jones, B. David Horn, and Lawrence Wells. Titanium elastic nails for pediatric tibial shaft fractures. J Child Orthop 2007 November; 1(5):281-286

17. Ozturkman Y. Dogrul C., balioglu MB. And Karli M. Intramedullary stabilization of pediatric diaphyseal femur fracture with elastic ender nails. Acta Orthop Traumatol Turc 2002; 36 (3): 220-7.

18. Cramer KE., Tornetta P. III, Spero CR, Alter S, Miraliakbar H, Teefey J. 'Ender rod fixation of femoral shaft fracture in children'. Clin Orthop and Rel Research 2000; 376: 119-123.

19. Gamal El-Adl, Mohamed F. Mostafa, Mohamed A. Khalil, Ahmed Enan. Titanium elastic nail fixation for paediatric femoral and tibial fractures. Acta Orthop. Belg 2009; 75: 512-520

20. Ferguson J, and Nicol RO. 'Entry spica treatment of pediatric femoral shaft fractures'. J Pediatr Orthop 2000; 20: 189-92.

21. KC Saikia, SK Bhuyan, TD Bhattacharya, SP Saikia. Titanium elastic nailing in femoral diaphyseal fractures of children in 6-16 years of age. Indian J Orthop 2007; 41:381-385. J Bone Joint Surg Br 86:954-957.

\begin{tabular}{|c|c|c|}
\hline Age in years & Number of patients & $\mathbf{\%}$ \\
\hline $5-8$ & 16 & 53.3 \\
\hline $9-12$ & 7 & 23.3 \\
\hline $13-16$ & 7 & 23.3 \\
\hline Total & $\mathbf{3 0}$ & $\mathbf{1 0 0 . 0}$ \\
\hline
\end{tabular}

Table 1: Age distribution of patients studied

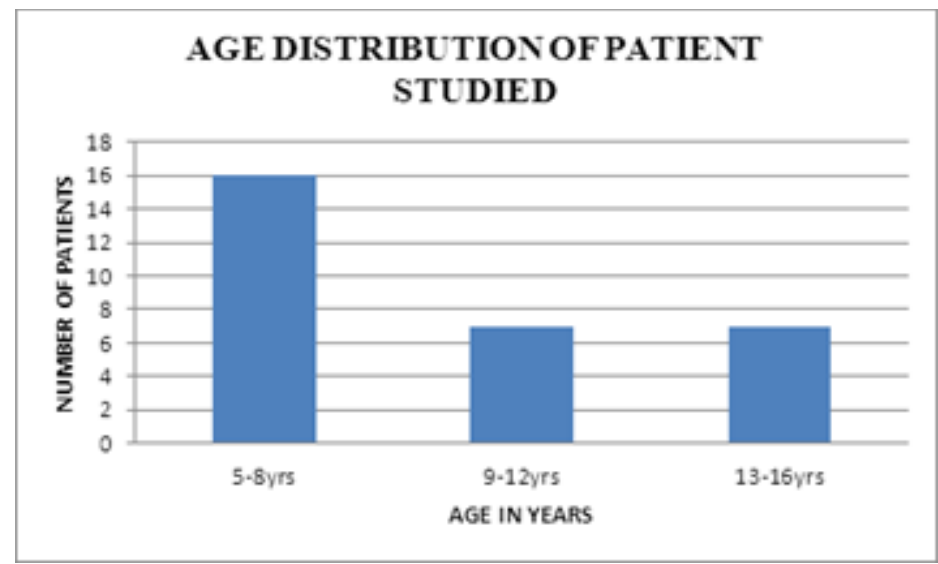

Graph 1: Age distribution of patients studied 


\begin{tabular}{|c|c|c|}
\hline Gender & Number of patients & $\mathbf{\%}$ \\
\hline Male & 24 & 80.0 \\
\hline Female & 6 & 20.0 \\
\hline Total & $\mathbf{3 0}$ & $\mathbf{1 0 0 . 0}$ \\
\hline
\end{tabular}

Table 2: Gender distribution of patients studied

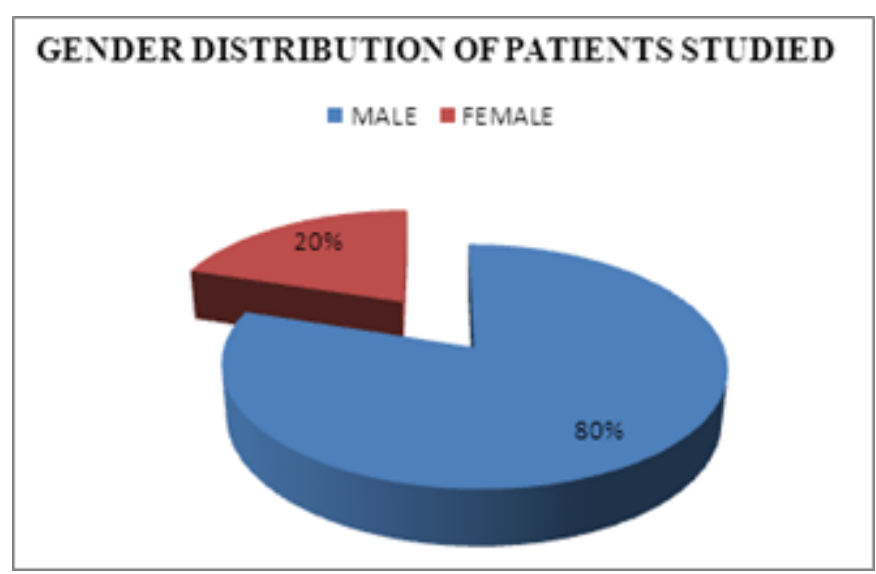

Graph 2: Gender distribution of patients studied

\begin{tabular}{|c|c|c|}
\hline Mode of injury & Number of patients & $\mathbf{\%}$ \\
\hline RTA & 18 & 60.0 \\
\hline Self-fall & 10 & 33.3 \\
\hline Fall from height & 2 & 6.66 \\
\hline Total & $\mathbf{3 0}$ & $\mathbf{1 0 0 . 0}$ \\
\hline
\end{tabular}

Table 3: Mode of Injury of patients studied

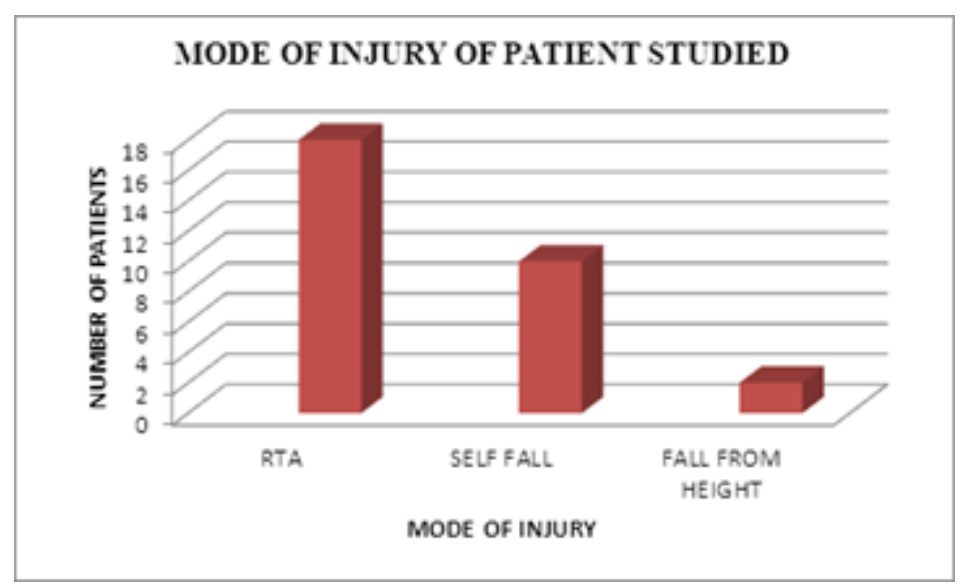

Graph 3: Mode of Injury of patients studied 


\section{ORIGINAL ARTICLE}

\begin{tabular}{|l|c|c|}
\hline Pattern of fracture & Number of patients & $\mathbf{\%}$ \\
\hline Transverse & 11 & 36.6 \\
\hline Oblique & 9 & 30.0 \\
\hline Spiral & 10 & 33.3 \\
\hline Segmental & 0 & 0.0 \\
\hline Communited & 0 & 0.0 \\
\hline \multicolumn{1}{|c|}{ Total } & $\mathbf{3 0}$ & $\mathbf{1 0 0 . 0}$ \\
\hline \hline
\end{tabular}

\section{Table 4: Pattern of fracture}

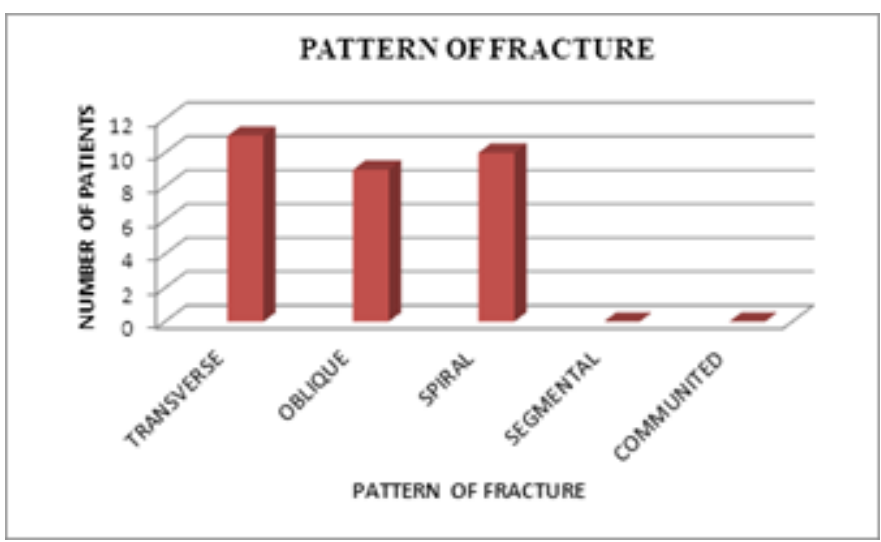

Graph 4: Pattern of fracture

\begin{tabular}{|c|c|c|}
\hline $\begin{array}{c}\text { Time of interval between } \\
\text { trauma \& surgery }\end{array}$ & $\begin{array}{c}\text { Number of } \\
\text { patients }\end{array}$ & $\mathbf{\%}$ \\
\hline$<2$ days & 16 & 53.3 \\
\hline 3-4 days & 8 & 26.6 \\
\hline 5-7 days & 4 & 13.3 \\
\hline$>7$ days & 2 & 6.6 \\
\hline Total & $\mathbf{3 0}$ & $\mathbf{1 0 0 . 0}$ \\
\hline
\end{tabular}

Table 5: Time interval between trauma and surgery

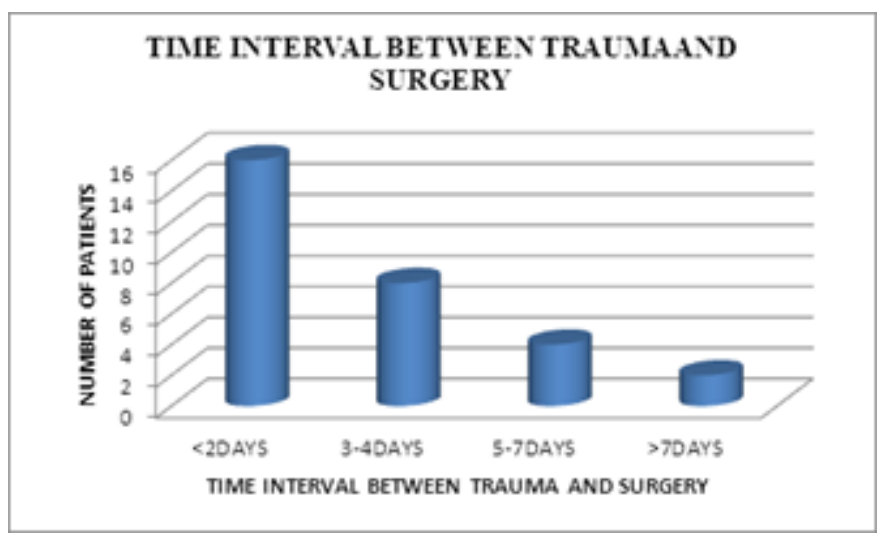

Graph 5: Time interval between trauma and surgery 
ORIGINAL ARTICLE

\begin{tabular}{|c|c|c|}
\hline $\begin{array}{c}\text { Duration of } \\
\text { surgery (min) }\end{array}$ & $\begin{array}{c}\text { Number of } \\
\text { patients }\end{array}$ & $\mathbf{\%}$ \\
\hline$<30$ & 5 & 16.6 \\
\hline $30-60$ & 16 & 53.3 \\
\hline $61-90$ & 7 & 23.3 \\
\hline $91-120$ & 2 & 6.7 \\
\hline Total & $\mathbf{3 0}$ & $\mathbf{1 0 0 . 0}$ \\
\hline
\end{tabular}

Table 6: Duration of surgery in minutes

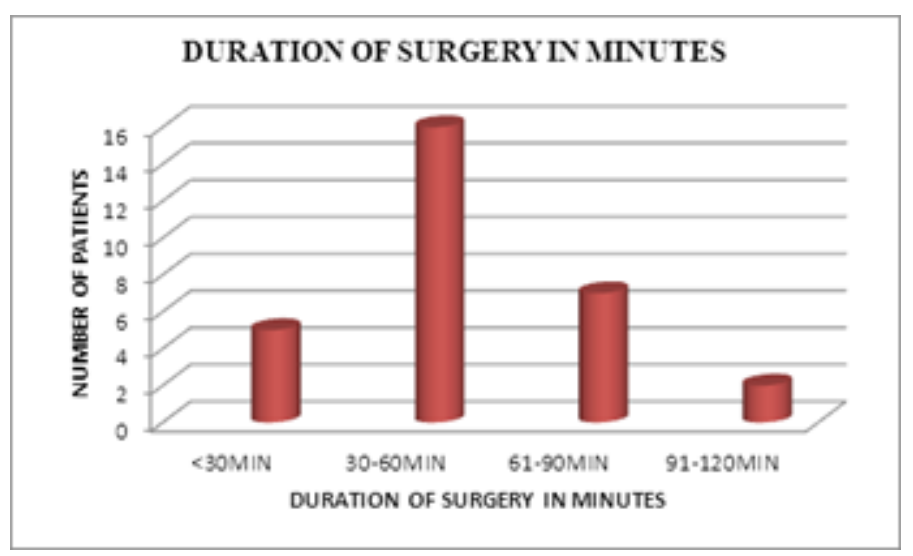

Graph 6: Duration of surgery in minutes

\begin{tabular}{|c|c|c|}
\hline Post-op immobilization & Number of patients & $\mathbf{\%}$ \\
\hline 6 weeks & 24 & 80.0 \\
\hline 9 weeks & 6 & 20.0 \\
\hline Total & $\mathbf{3 0}$ & $\mathbf{1 0 0 . 0}$ \\
\hline
\end{tabular}

Table 7: Post-operative Immobilization

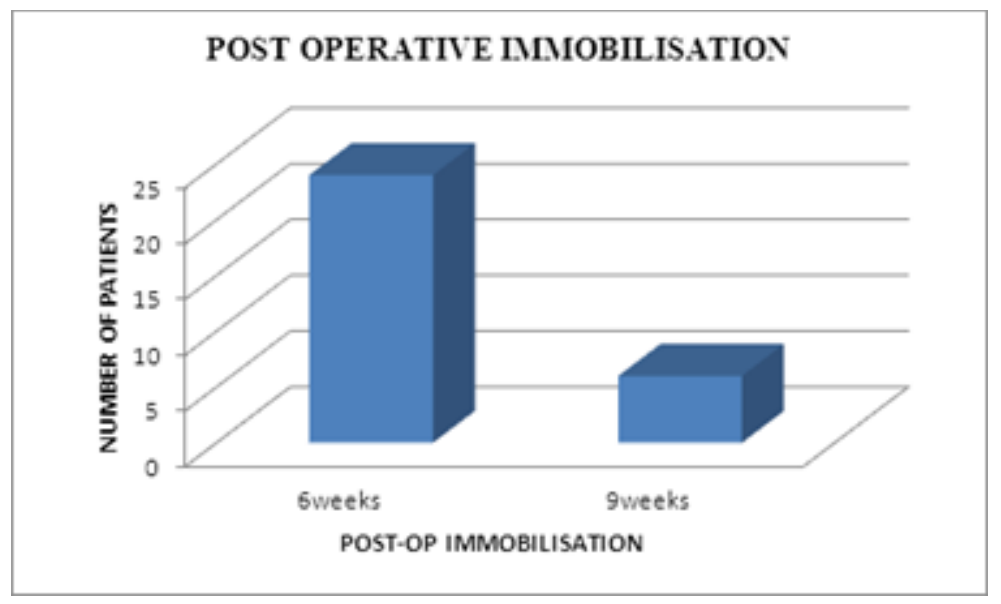

Graph 7: Post-operative Immobilization 


\section{ORIGINAL ARTICLE}

\begin{tabular}{|c|c|c|}
\hline Duration of stay (days) & Number of patients & $\%$ \\
\hline$<7$ & 21 & 70.0 \\
\hline $8-10$ & 3 & 10.0 \\
\hline $11-15$ & 4 & 13.3 \\
\hline$>15$ & 2 & 6.6 \\
\hline Total & 30 & 100.0 \\
\hline
\end{tabular}

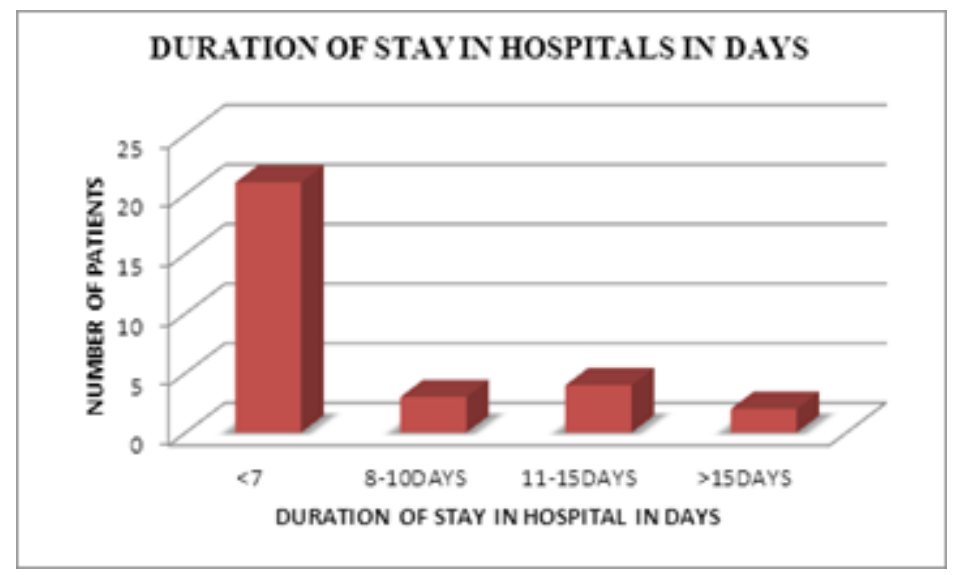

\section{Graph 8: Duration of stay in hospital in days}

\begin{tabular}{|c|c|c|}
\hline Time for union & Number of patients & $\mathbf{\%}$ \\
\hline$</=12$ weeks & 23 & 76.6 \\
\hline$>12-18$ weeks & 5 & 16.6 \\
\hline$>18-24$ weeks & 2 & 6.6 \\
\hline Total & $\mathbf{3 0}$ & $\mathbf{1 0 0 . 0}$ \\
\hline \multicolumn{2}{|c|}{ Table 9: Time for union } \\
\hline
\end{tabular}

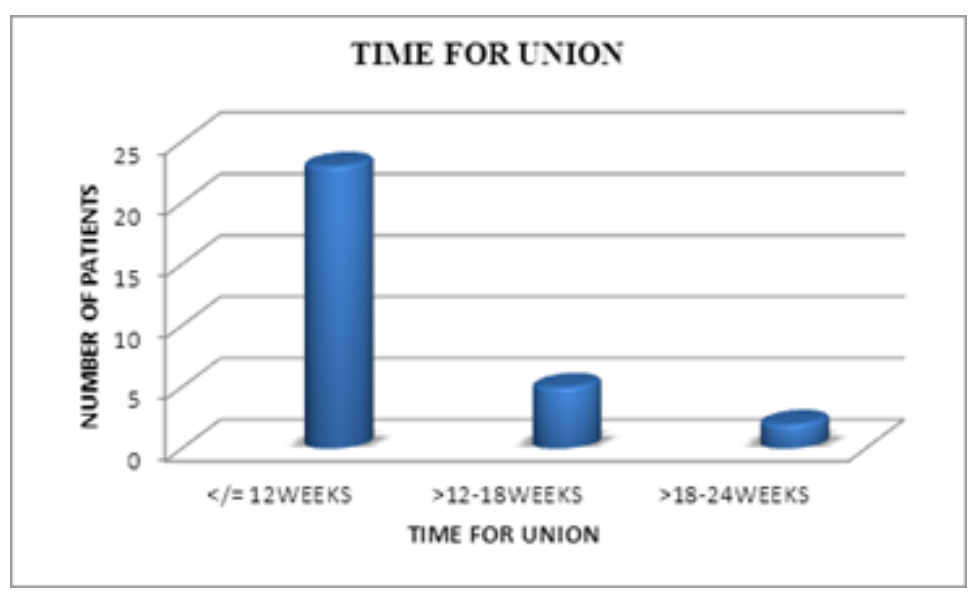

Graph 9: Time for union 


\begin{tabular}{|c|c|c|}
\hline $\begin{array}{c}\text { Time of } \\
\text { full weight bearing }\end{array}$ & $\begin{array}{c}\text { Number of patients } \\
\text { (n=30) }\end{array}$ & \% \\
\hline$\leq 12$ weeks & 23 & 76.6 \\
\hline$>12-18$ weeks & 5 & 16.6 \\
\hline$>18-24$ weeks & 2 & 6.6 \\
\hline
\end{tabular}

Table 10: Time of full weight bearing

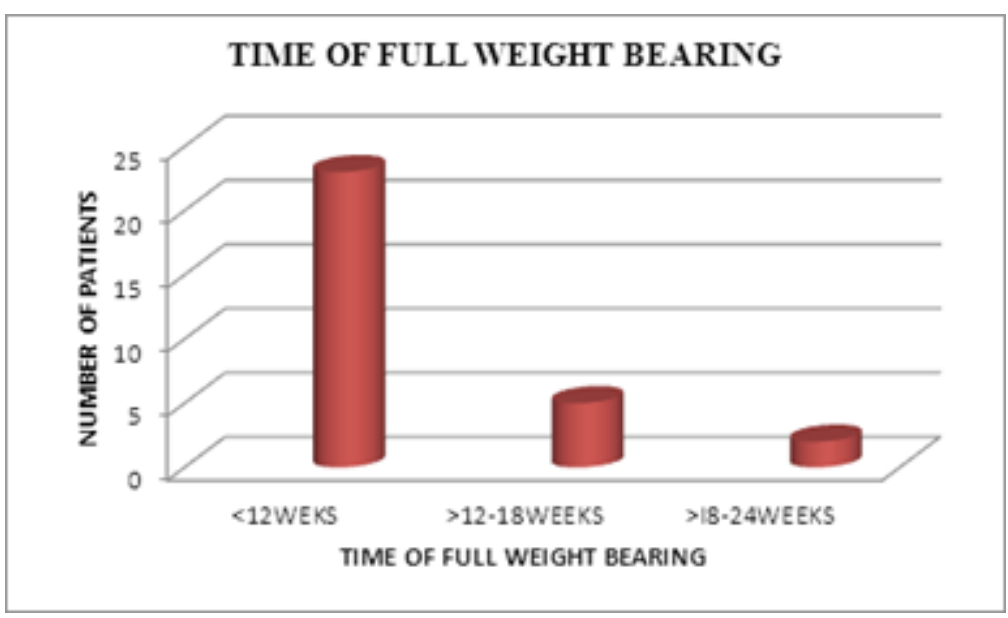

Graph 10: Time of full weight bearing

\begin{tabular}{|c|c|c|c|c|}
\hline & Minor & Major & Nil & Total \\
\hline No. of Patients & 10 & - & 20 & 100 \\
\hline Percentage & 33.33 & - & 66.66 & 100 \\
\hline
\end{tabular}

Table 11.A: Complications

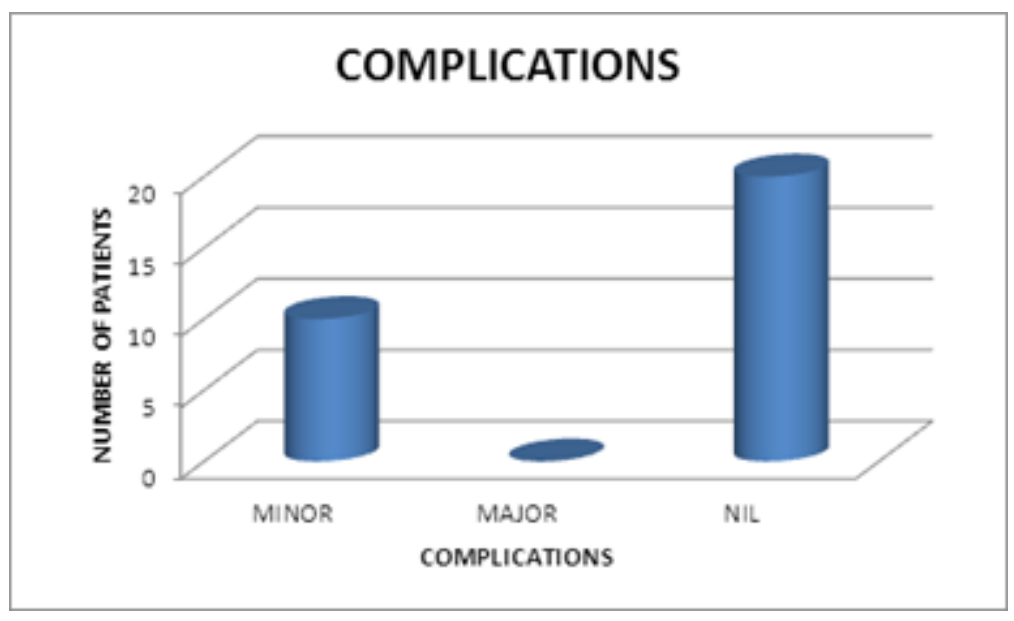

Graph 11.A: Complications 


\section{ORIGINAL ARTICLE}

\begin{tabular}{|c|c|c|}
\hline Complications & No. of cases & Percentage \\
\hline Pain & 4 & 13.3 \\
\hline Infection & \multirow[b]{2}{*}{1} & \multirow[b]{2}{*}{3.3} \\
\hline Superficial & & \\
\hline Deep & - & - \\
\hline Inflammatory reaction & - & - \\
\hline Delayed union and non-union & - & - \\
\hline Limb lengthening & \multirow[b]{2}{*}{2} & \multirow[b]{2}{*}{6.66} \\
\hline$<2 \mathrm{~cm}$ & & \\
\hline$>2 \mathrm{~cm}$ & - & - \\
\hline Limb shortening & \multirow[b]{2}{*}{-} & \multirow[b]{2}{*}{-} \\
\hline$<2 \mathrm{~cm}$ & & \\
\hline$>2 \mathrm{~cm}$ & - & - \\
\hline Nail back out & 1 & 3.3 \\
\hline Mal alignment & \multirow[b]{2}{*}{2} & \multirow{2}{*}{6.6} \\
\hline a. Varus angulation & & \\
\hline b. Valgus angulation & 1 & 3.3 \\
\hline c. Anterior angulation & - & - \\
\hline d. Posterior angulation & - & - \\
\hline e. Rotational malalignment & - & - \\
\hline Bursa at the tip of the nail & 3 & 10.0 \\
\hline Sinking of the nail into the medullary cavity & - & - \\
\hline
\end{tabular}

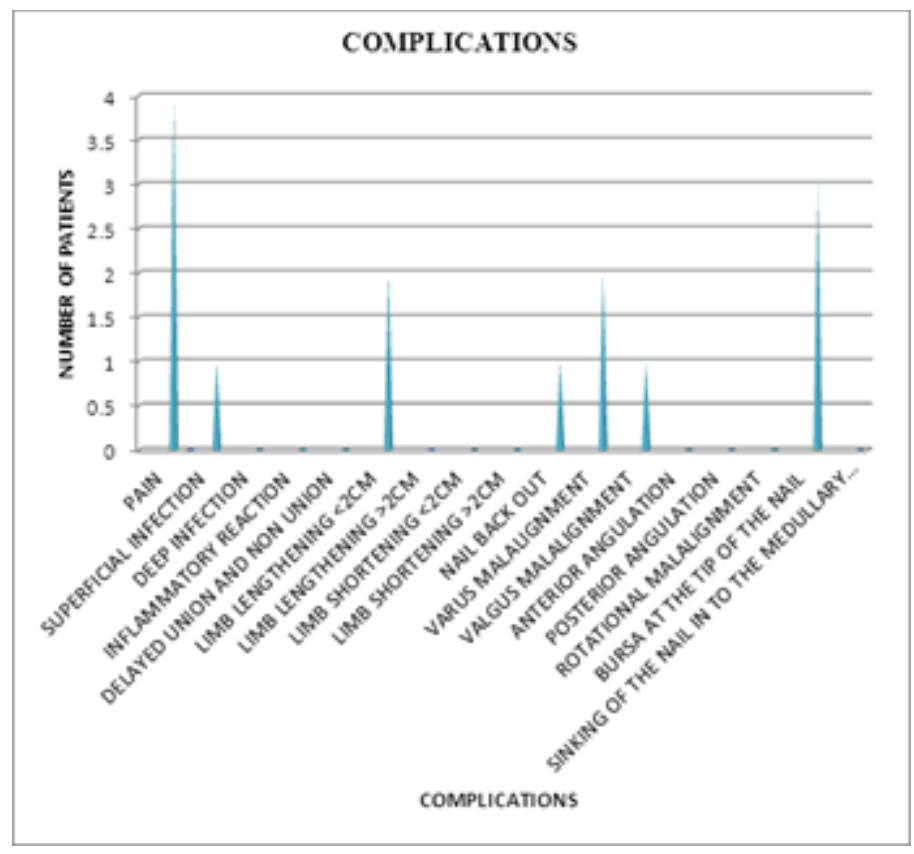

Graph 11.B: Complications 


\section{ORIGINAL ARTICLE}

\begin{tabular}{|c|c|c|}
\hline Outcome & Number of patients $(\mathbf{n = 3 0 )}$ & $\mathbf{\%}$ \\
\hline Excellent & 20 & 66.67 \\
\hline Satisfactory & 10 & 33.34 \\
\hline Poor & 0 & 0.0 \\
\hline
\end{tabular}

Table 12: Outcome

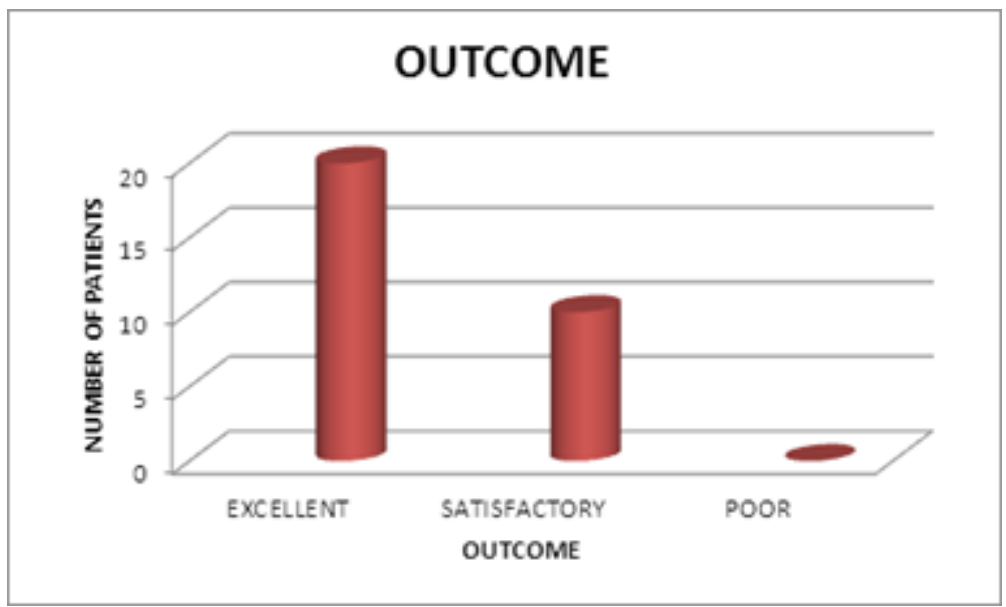

Graph 12: Outcome

\section{RADIOLOGICAL \& CLINICAL PHOTOGRAPHS:}

\section{CASE NO: 1}

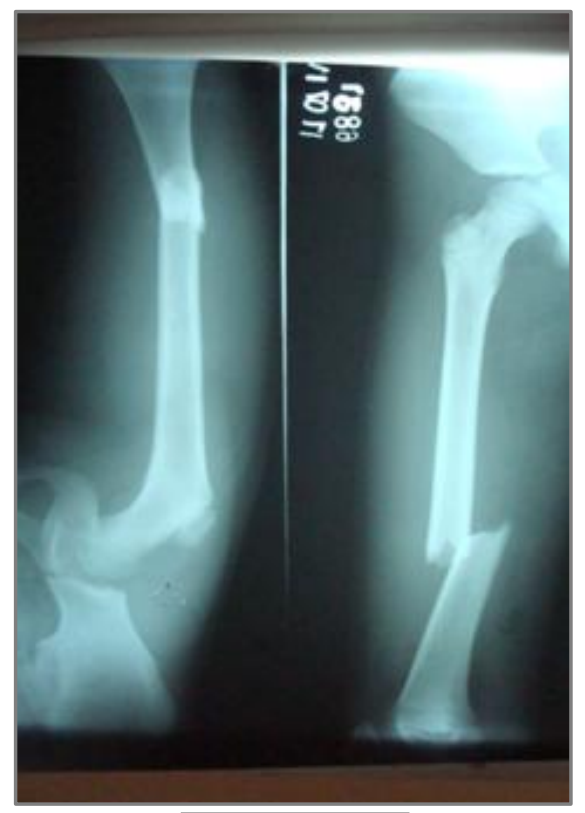

PRE - OP

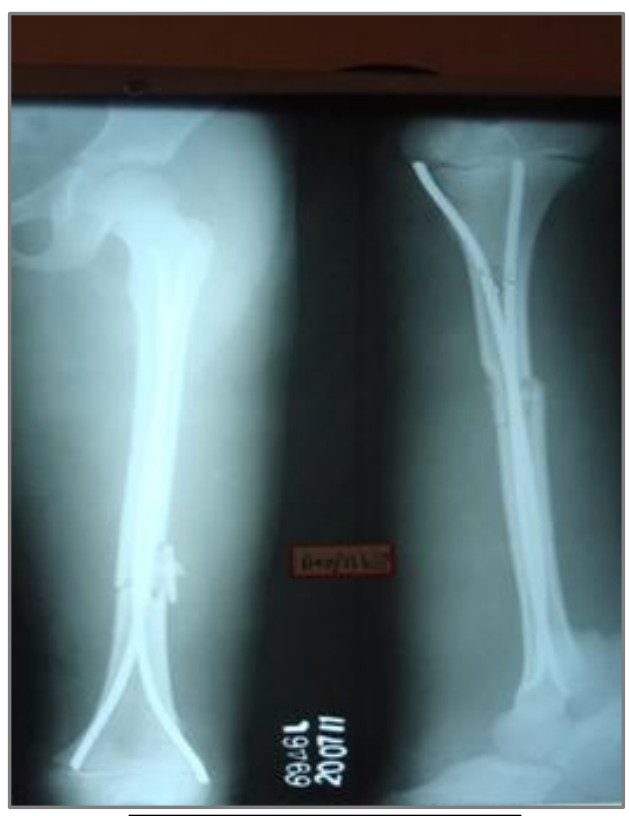

POST-OP: 3 WEEKS 


\section{ORIGINAL ARTICLE}

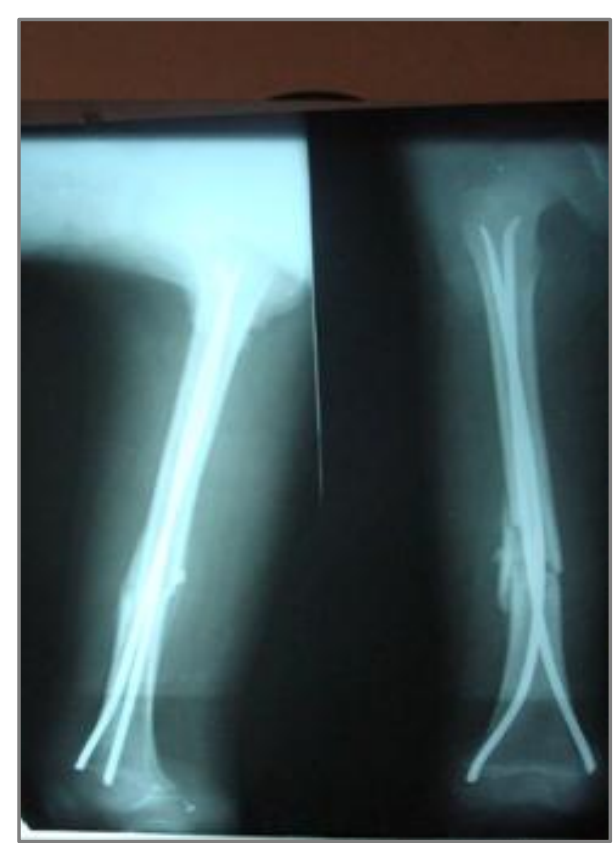

POST-OP: 6 WEEKS

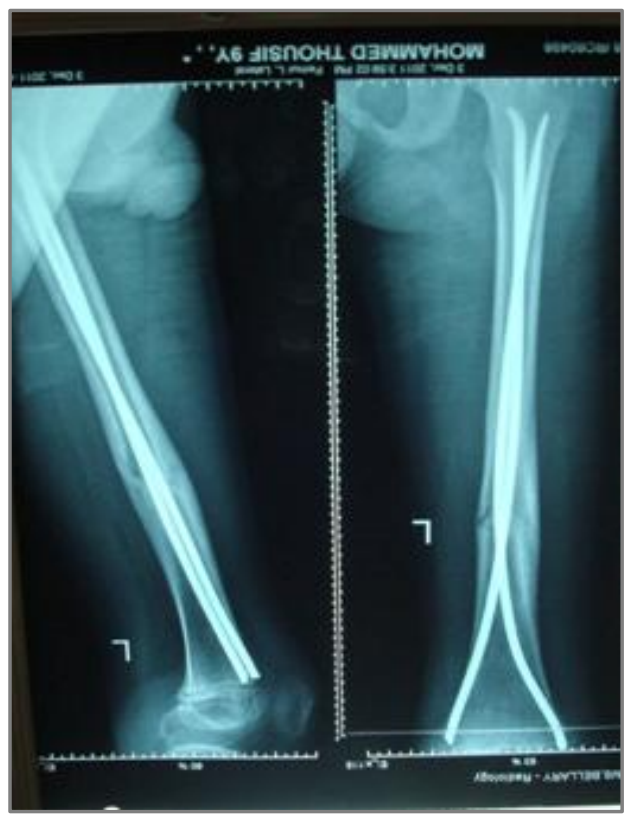

POST-OP: 24 WEEKS

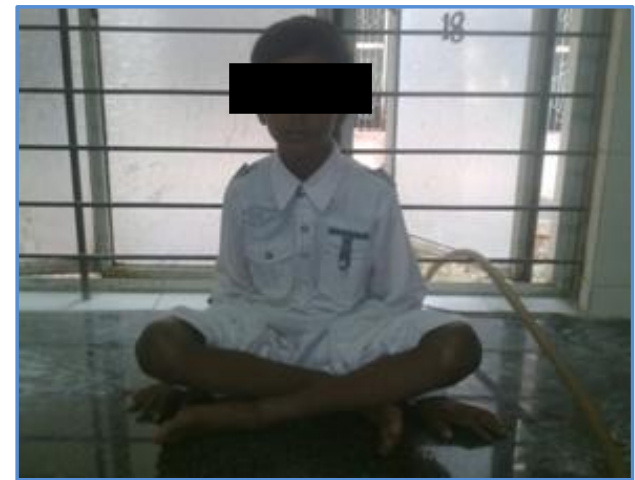

SITTING CROSS LEGGED

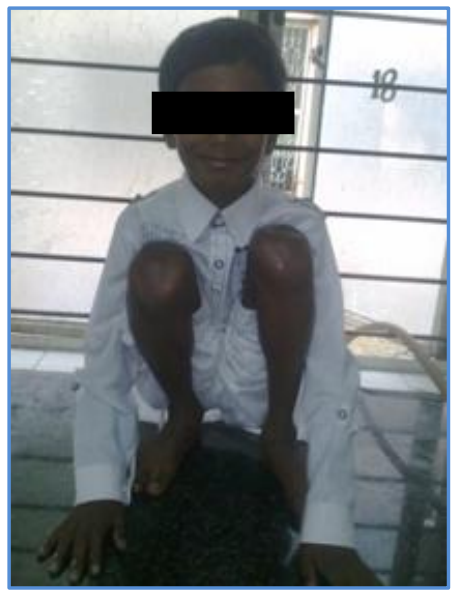

SQUATTING 


\section{ORIGINAL ARTICLE}

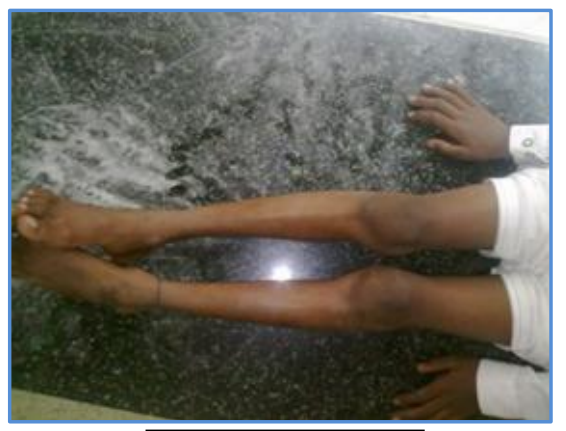

EXTENSION

CASE NO: 2
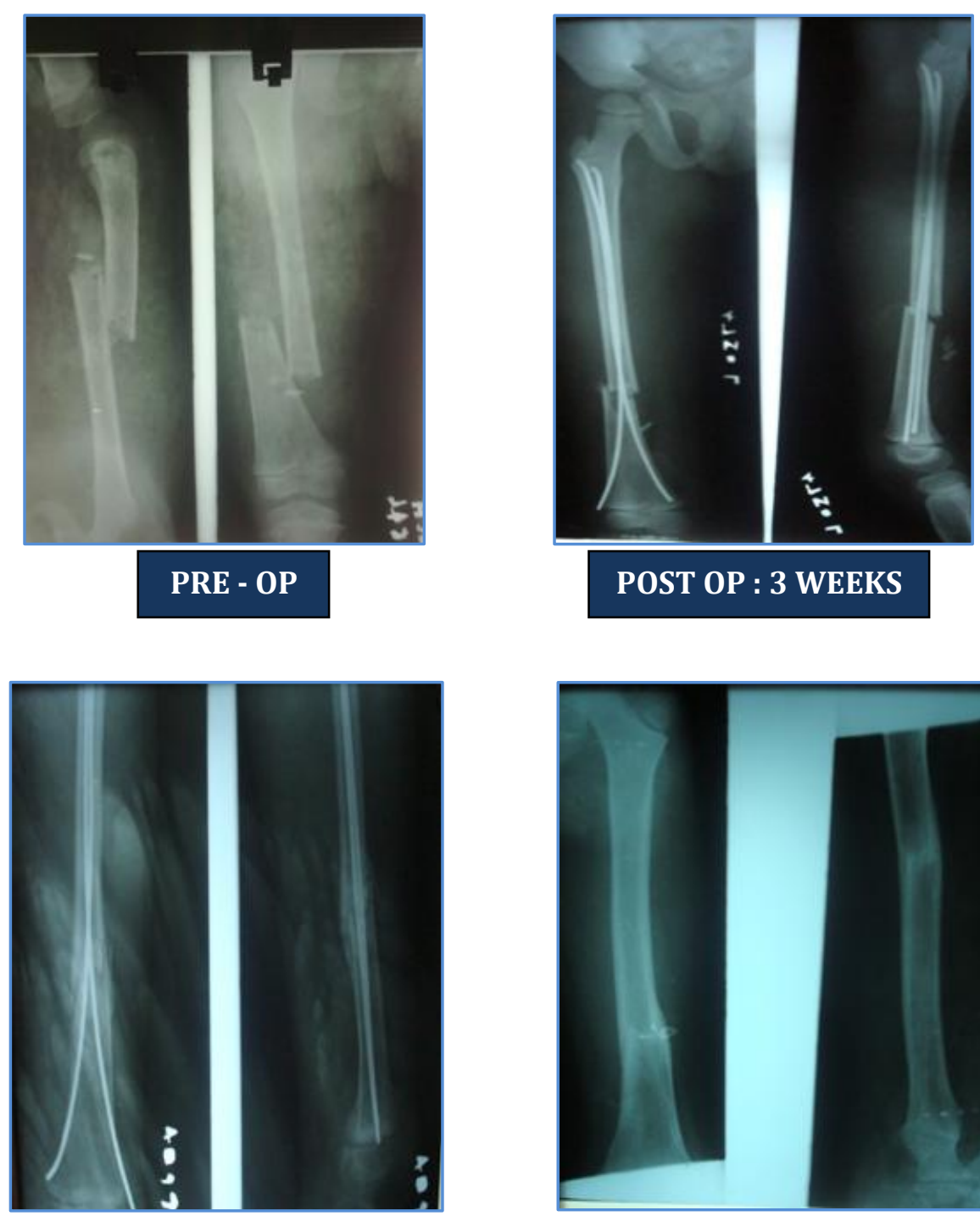

POST OP: 12 WEEKS

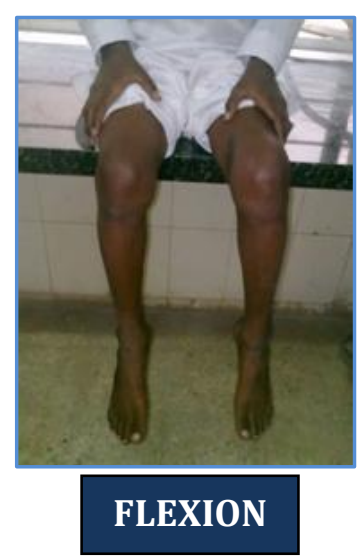

FLEXION

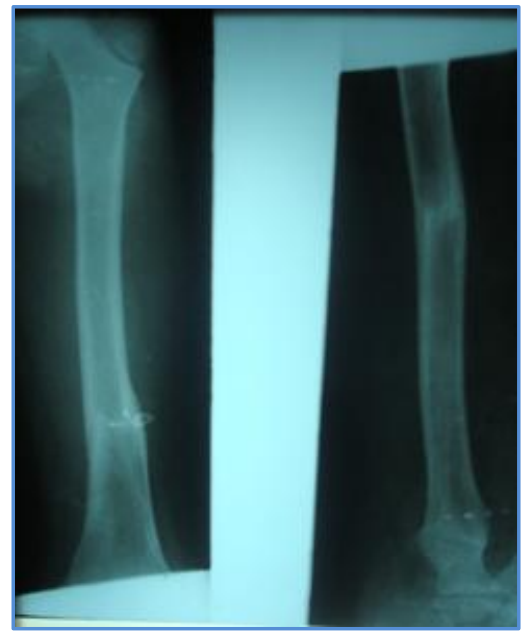

POST OP: 24 WEEKS AFTER IMPLANT REMOVAL 


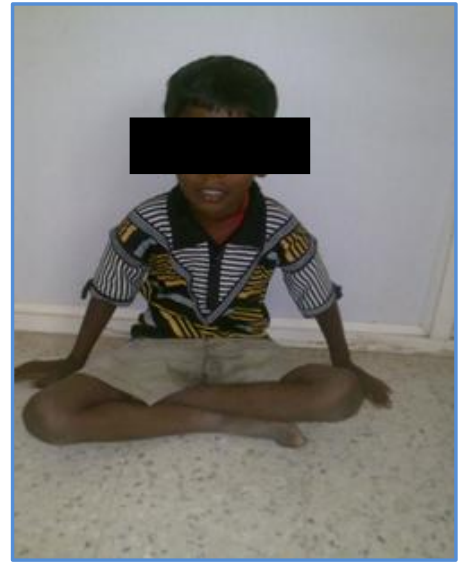

CROSS LEGGED

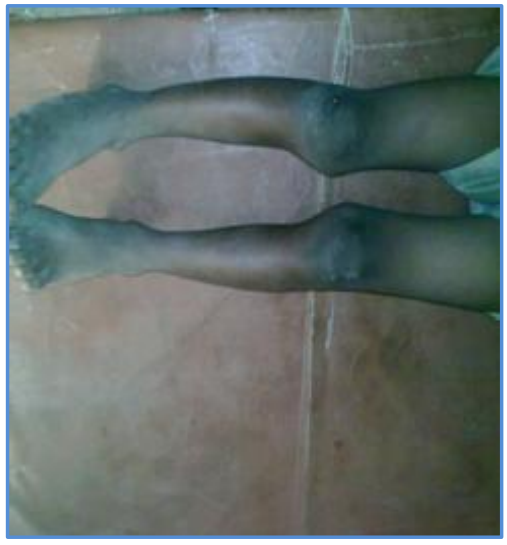

EXTENSION

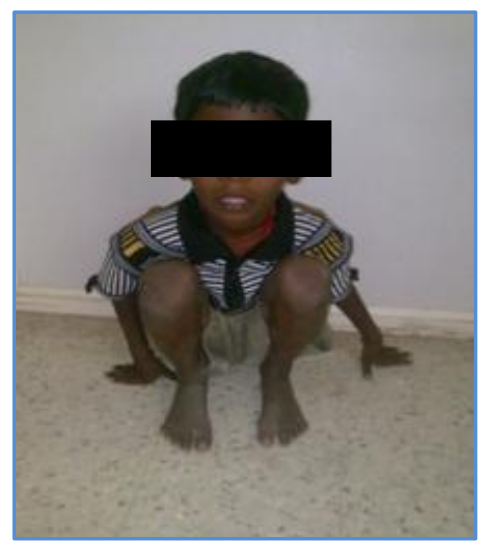

\section{SQUATTING}

\section{AUTHORS:}

1. Prabhakar Venkataramana

2. Siddarth Mahesh

3. Srinivas Nagendra G.

\section{PARTICULARS OF CONTRIBUTORS:}

1. Senior Resident, Department of Orthopaedics, Sapthagiri Medical College \& Hospital.

2. Assistant Professor, Department of Orthopaedics, Sapthagiri Medical College \& Hospital.

3. Assistant Professor, Department of Orthopaedics, Sapthagiri Medical College \& Hospital.

\section{NAME ADDRESS EMAIL ID OF THE} CORRESPONDING AUTHOR:

Dr. Prabhakar V, \#55, Rajiv Gandhi Road, J.P. Nagar, $6^{\text {th }}$ Phase Post, Jaraganahalli, Bangalore - 560078.

E-mail: dr.prabhakar.venkat@gmail.com

Date of Submission: 02/02/2014. Date of Peer Review: 03/02/2014. Date of Acceptance: 14/02/2014. Date of Publishing: 28/02/2014. 